\title{
USO E CONSERVAÇÃO DA ICTIOFAUNA NO ECOTURISMO DA REGIÃO DE BONITO, MATO GROSSO DO SUL: O MITO DA SUSTENTABILIDADE ECOLÓGICA NO RIO BAÍA BONITA (AQUÁRIO NATURAL DE BONITO)
}

\author{
José Sabino ${ }^{1}$ \& Luciana Paes de Andrade ${ }^{1,2}$ \\ Biota Neotropica v3 (n2) - http://www.biotaneotropica.org.br/v3n2/pt/abstract?point-of-view+BN00403022003 \\ Recebido em 18/06/2003 \\ Publicado em 01/07/2003
${ }^{1}$ Universidade para o Desenvolvimento do Estado e da Região do Pantanal - UNIDERP
Mestrado em Meio-Ambiente e Desenvolvimento Regional
Laboratório de Biodiversidade, Ecologia e Conservação de Ecossistemas Aquáticos
79290-000 Bonito, Mato Grosso do Sul, Brasil
e-mail: jsabino@bonitonline.com.br
${ }^{2}$ Universidade de São Paulo, Instituto de Biociências, Departamento de Zoologia
Doutoranda do Programa de Pós-Graduação em Zoologia
e-mail: lucituca@bonitonline.com.br

\begin{abstract}
The Bonito region, in Mato Grosso do Sul State, stand out in Brazil as national reference of example of correct practices in the ecotourism. In spite of progresses in the tourist operation, a three years study of environmental monitoring in Rio Baía Bonita indicates losses of biodiversity portion, very probably due to the visitation excess. Proposed of management and of low impact tourism practices, with careful operation protocol and reduction of the carrying capacity, they were rejected by the company responsible for the operation in the place. Unfortunattly, this event indicates that there is still an enormous gap among the support that the Conservation Biology could give to the sustainable tourist operation. The model of tourist activity developed by the land-owners is conduct essentially by economical parameters in detriment of the environmental ones, and the conservationism don't get ahead of the rhetoric. The fragility and uniqueness, as the one of Natural Aquarium area, request scientific contributions for wildlife conservation and environment sustainable use in long term.
\end{abstract}

Key words: Biodiversity, Wildlife Conservation, Ecotourism, Economic Value of Nature, Sustainable Tourism, Fishes, Bodoquena Plateau, Mato Grosso do Sul

Resumo

A região de Bonito, Mato Grosso do Sul, desponta no Brasil como referência nacional de exemplo de práticas corretas no ecoturismo. Apesar de avanços na operação, um estudo de três anos de monitoramento ambiental do Rio Baía Bonita indica perdas de parcela de biodiversidade, muito provavelmente decorrente do excesso de visitação. Propostas de manejo e de turismo de mínimo impacto, com cuidadoso protocolo de operação e redução da capacidade de carga, foram rejeitadas pela empresa responsável pela operação no local. Este evento indica que, infelizmente, ainda há uma enorme lacuna entre o suporte que a Biologia da Conservação poderia dar à operação turística. O modelo de atividade turística desenvolvido pelos empresários é balizado essencialmente por parâmetros econômicos em detrimento dos ambientais, que não passam da retórica. A delicadeza e unicidade de ambientes como o do "Aquário Natural”, contudo, requer aportes científicos para a efetiva conservação da fauna e da sustentabilidade ambiental no longo prazo.

Palavras-chave: Biodiversidade, Conservação, Ecoturismo, Valoração Econômica da Natureza, Turismo Sustentável, Peixes, Planalto da Bodoquena, Mato Grosso do Sul

http://www.biotaneotropica.org.br 


\section{Introdução}

Who hears the fishes when they cry?

Henry David Thoreau (1849)

A região de Bonito, localizada no Planalto da Bodoquena, Mato Grosso do Sul, desponta no cenário nacional como exemplo de práticas corretas de ecoturismo (Sabino, 2002). De fato, avanços conceituais e operacionais, tais como obrigatoriedade de acompanhamento de guia credenciado e limites na capacidade de visitação em alguns atrativos turísticos (mesmo que empiricamente estabelecidos), foram conquistas que ajudaram a conservar parte da biota dos ecossistemas visitados (Sabino \& Andrade, 2002).

Uma longa e complexa combinação de processos geológicos e evolutivos fizeram das nascentes da região sistemas naturais de elevada biodiversidade, com alto grau de unicidade e beleza cênica. A formação geológica do Planalto da Bodoquena explica parte da plasticidade das surgências. Estudos mostram que o subsolo do planalto é formado por rochas calcárias puras, originadas há 550 milhões de anos. A pureza e a antiguidade das rochas tornam as águas límpidas (Boggiani, 1999). O calcário dissolvido na água absorve e decanta as poucas impurezas restantes, tornando a água mais cristalina ainda. Em alguns locais, a visibilidade debaixo da água chega a 60 m, uma das águas mais transparentes do mundo (Sabino \& Andrade, 2002).

A rica biodiversidade da Bodoquena é resultado de outros tantos milhões de anos de evolução biológica. Uma complexa combinação de fatores naturais permite que plantas aquáticas, peixes e toda sorte de invertebrados coexistam em nascentes de águas absolutamente cristalinas (Figura 1). Em conjunto, os organismos formam uma intrincada trama de vida, que conecta desde uma alga unicelular aos grandes predadores dos rios, como os dourados e as ariranhas (Sabino, 2002).

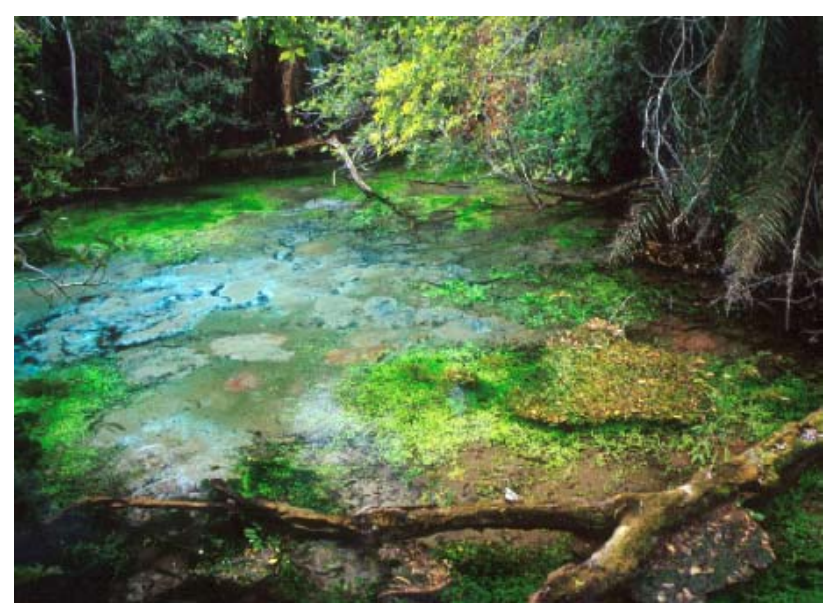

Figura 1. Nascente do rio Sucuri, Bonito, Mato Grosso do Sul, mostrando a rica vegetação ripária e a elevada transparência da água (Foto: José Sabino, 23/06/2001).
Aumento da visitação causa riscos à biota

A atividade turística, quando mal conduzida, pode afetar negativamente os componentes sensíveis do ambiente (e.g., Bratton, 1985; Garber \& Burger, 1995; Cole, 1997). Para a prática correta do ecoturismo, devem ser estabelecidos protocolos de visitação que visam minimizar o conflito entre recreação e conservação da natureza (Cole, 1993), preparando o visitante para compreender e respeitar as características dos ambientes (Niefer \& Silva, 1999; Mitraud, 2001; Sabino \& Andrade, 2002).

Dados oficiais do Conselho Municipal de Turismo de Bonito (COMTUR) apontam para o crescimento da atividade turística da região, com aproximadamente 60 mil visitantes em 2002. Acomodar e ajustar o crescente número de visitantes em áreas naturais, sem sacrificar sua integridade ecológica, tem se tornado o desafio central do turismo sustentável (Cifuentes, 1992; Takahashi, 1997; Mitraud, 2001; Sabino \& Andrade, 2002).

Além das preocupações éticas da conservação ambiental, a implantação de empreendimentos ecoturísticos impõe exigências legais ao empreendedor, que deve providenciar o licenciamento ambiental (Lei Federal $N^{\circ}$ 6.938/ 81, e Resolução SEMA/MS No 331/98). Estas obrigações legais implicam -entre outras condições- na elaboração de um plano de uso turístico e controle dos impactos causados pela visitação, através de um programa de monitoramento ambiental.

Com base nas exigências anteriores, em junho de 2000, a pedido da Baía Bonita Tours, elaboramos e implantamos um "Programa de Monitoramento do Rio Baía Bonita", com os seguintes objetivos: orientar a execução de medidas de manejo e gestão ambiental, visando disciplinar e atribuir valores educacionais e conservacionistas, controlando e atenuando os impactos da visitação ao local (Sabino \& Andrade, 2002).

O Programa de Monitoramento do Rio Baía Bonita é baseado fundamentalmente na literatura corrente, com destaque para os trabalhos de Roggenbuck \& Lucas (1987), Goldsmith (1994), Sabino (1999), Garay \& Dias (2001) e Mitraud (2001). Para avaliar a qualidade ambiental, destacamse métodos que monitorem variáveis e descritores das pressões de atividades humanas sobre o ambiente em longo prazo (Tolmasquim, 2001; Rizzo, 2001; Sabino \& Andrade, 2002). O conhecimento dos diferentes componentes bióticos e abióticos, bem como aspectos do funcionamento dos ecossistemas, fornece ferramentas de gestão ambiental e gera estudos paralelos de ecologia (e.g., Sabino \& Sazima, 1999; Reys et al., 2000) que retroalimentam a gestão ambiental, fortalecendo exploração turística de mínimo impacto por meio da educação conservacionista.

http://www.biotaneotropica.org.br 


\section{Procedimentos de proteção implantados no rio e seu entorno}

Entre junho de 2000 e dezembro de 2002, foram implantadas e mantidas as seguintes medidas mitigadoras do impacto de visitação:

a) redução progressiva até a proibição total de oferta de milho para os peixes por parte dos visitantes. A oferta de alimento artificial pode gerar problemas nas cadeias tróficas naturais dos organismos aquáticos, levando a alterações deletérias do ecossistema;

b) proibição da passagem de botes infláveis sobre as tufas calcárias do rio Formoso, localizadas próximas ao rio Baía Bonita. Estas tufas funcionam como diques naturais e regulam o nível e vazão dos rios;

c) implantação de calçamento de madeira em 100\% das trilhas terrestres, visando reduzir a compactação do solo, o impacto do pisoteio da vegetação, o transporte de sedimento para dentro da água, e o desbarrancamento nas regiões marginais ao rio, além de aumentar a segurança do usuário;

d) realização de treinamento do visitante em piscina, visando reduzir o impacto sobre a nascente do rio. A visitação ao rio é feita em grupos de no máximo nove turistas, acompanhados obrigatoriamente de um guia.

\section{Visitante adequadamente treinado minimiza risco ambiental}

A magnitude do impacto de visitação é altamente influenciada pelo comportamento do visitante (Cole \& Landres, 1996; Cole, 2000). Assim, o treinamento dos visitantes em piscina deve ser mantido como um dos procedimentos centrais da visitação de mínimo impacto ao Rio Baía Bonita, notadamente à sua nascente (Aquário Natural), ambiente frágil e de grande importância cênica e biológica. O uso obrigatório de roupa de neoprene, combinado com colete salva-vidas e sandálias de borracha, aumenta a flutuabilidade do visitante e, por consequiência, amplia os cuidados com o delicado sedimento inconsolidado do leito do rio e das macrófitas aquáticas (figura 2). As macrófitas, por sua vez, são fragilmente implantadas no leito e dão suporte à vegetação epifítica, além de servirem de abrigo e alimento para numerosas espécies de invertebrados aquáticos e peixes, de modo similar ao registrado em ambientes pantaneiros (Pott \& Pott, 2000) e amazônicos (Sanchéz-Botero \& Araújo-Lima, 2001).

Salvo intervenções de ordem estrutural e de segurança, os sítios de visitação não devem sofrer adaptações aos visitantes; estes é que deverão ser preparados para a visitação às áreas naturais (Cole, 1993;

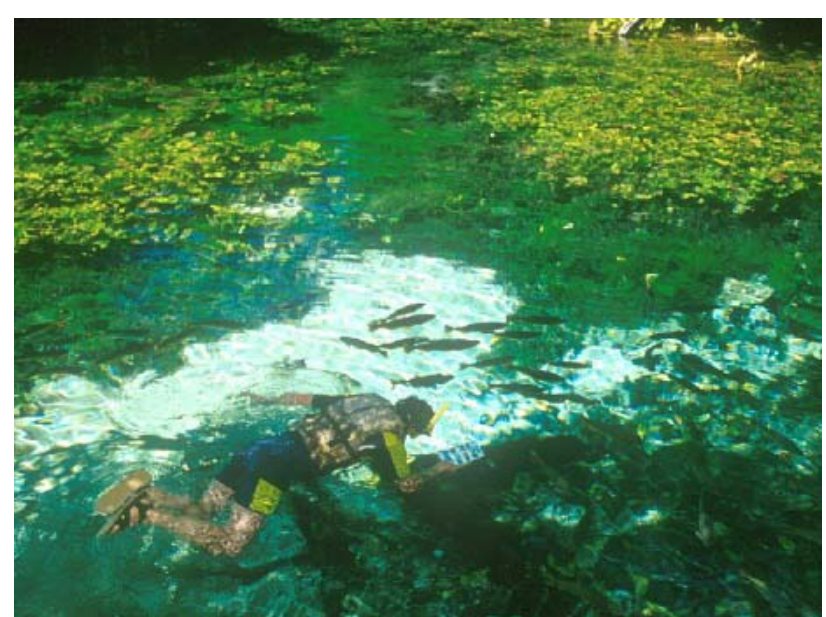

Figura 2. O uso obrigatório de equipamentos aumenta a flutuabilidade do visitante e, por conseqüência, amplia os cuidados com o delicado sedimento inconsolidado do leito do rio e das macrófitas aquáticas do Aquário Natural, rio Baía Bonita, Bonito (Foto: José Sabino, 10/01/2003).

Lindberg \& Hawkins, 1993). No caso específico do rio Baía Bonita, além de obrigatório a todo visitante, o treinamento deve ser ampliado em qualidade e tempo. O correto é que este treinamento seja feito com todos os usuários e dure pelo menos 20 minutos, tempo suficiente para que os iniciantes sintam-se adaptados aos equipamentos e procedimentos. O problema da má qualidade do treinamento na piscina é nitidamente acentuado nos períodos de alta temporada, em que os grupos são conduzidos com extrema rapidez em cada parte do passeio, o que inclui pouco tempo destinado à piscina. Alguns guias de turismo responsáveis pela condução de visitantes relataram esta dificuldade, embora não tenham ficado à vontade para expressar este quadro de atropelo da operação, com receio de retaliações por parte da empresa.

Todos os cuidados e procedimentos citados anteriormente resultaram em ganhos ambientais e deveriam ser mantidos e aplicados rigorosamente como pontos estruturais para visitação de mínimo impacto ao rio Baía Bonita e não apenas como "fachada ecológica". Um caso de exploração turística descontrolada, em ambiente aquático similar, serve de alerta para a operação no Rio Baía Bonita: ao longo da década de 1990, como conseqüência da visitação desordenada, a nascente do Rio Pratinha, localizado na Chapada Diamantina, Bahia, teve a perda da cobertura de macrófitas aquáticas e redução acentuada da biodiversidade de peixes e invertebrados.

\section{Monitoramento da fauna aquática}

O monitoramento está focado principalmente nas observações subaquáticas dos peixes, conforme descrito por Sabino (1999). É dada prioridade para espécies que 
ocupam posição de topo na cadeia alimentar (e.g., dourado, Salminus maxillosus), e espécies residentes que tenham processos reprodutivos em biótopos delicados na área da nascente (e.g., joaninha, Crenicichla lepidota). Espécies da ictiocenose com requisitos alimentares especiais, como cascudos do gênero Farlowella, que apresentam distribuição gregária e são muito sensíveis a alterações da disponibilidade de algas, também servem como bons bioindicadores. A presença destas espécies, bem como aspectos de seu comportamento alimentar, reprodutivo e social constituem indicadores do estado de conservação do ambiente.

Espécies de interesse turístico, como piraputanga (Brycon hilarii), curimbatá (Prochilodus lineatus) e matogrosso (Hyphessobrycon eques) também têm suas populações monitoradas, visto que sua presença é importante na manutenção do principal atrativo turístico do passeio. No caso da piraputanga e do curimbatá, informações de abundância e presença ou ausência estão sendo úteis para estudos iniciais de migração e reprodução de peixes no sistema do Rio Formoso, o principal rio da região.

\section{Monitoramento indica perdas de biodiversidade}

Dados do monitoramento indicam que o impacto dos visitantes sobre a ictiofauna tem aumentado. Até o final de 2001, os peixes não apresentavam redução em riqueza de espécies, representada por cerca de 30 espécies (Sabino \& Sazima, 1997). Entretanto, a partir de meados de 2002, algumas espécies bioindicadoras não foram registradas e outras diminuíram em ocorrência. É digna de nota a ausência de Farlowella, não detectada nos últimos três monitoramentos (junho, setembro e dezembro de 2002). A redução ou mesmo o desaparecimento das populações locais destes cascudos pode ser resultado da diminuição da oferta de alimento natural (algas microscópicas que recobrem macrófitas aquáticas ou rochas do leito), em conseqüência da turbulência causada pelos movimentos dos turistas e pelos remos dos barcos, ou ainda por processos de eutrofização e favorecimento de algas filamentosas, registradas em eventos de reprodução explosivos.

O número de registros de Salminus maxillosus também diminuiu nos últimos três monitoramentos (junho, setembro e dezembro de 2002). A redução da densidade populacional desta espécie pode ser parcialmente explicada por flutuações naturais, vinculadas a migrações reprodutivas (piracema; observações de dezembro de 2002). No entanto, nos monitoramentos de junho e setembro de 2002 não foi encontrada nenhuma outra causa natural que justifique a diminuição destes registros, que caíram de 8 a 13 indivíduos por transecto (registros médios de 2001 e do primeiro semestre de 2002) para 3 a 5 indivíduos por transecto (junho e setembro de 2002).

A população de Brycon hilarii no rio Baía Bonita, acompanhada por métodos de censo visual e registro fotográfico, é estável ao longo do ano, com número de indivíduos variando entre aproximadamente 350 e 500 . A exceção desta densidade elevada é no período de piracema, quando há uma nítida redução de indivíduos. O pico desta redução se dá nos meses de novembro e dezembro, quando a maioria das piraputangas desloca-se ao Rio Formoso para reprodução.

No auge da piracema (em geral, em dezembro e janeiro), o Rio Baía Bonita recebe grupos de peixes sexualmente maduros, principalmente das espécies Brycon hilarii e Prochilodus lineatus, que usam a área para desova. Estes eventos demonstram que a área é sítio de reprodução e desova destas espécies migradoras, evidenciando a importância ecológica da Baía Bonita em escala regional. O local funciona como berçário natural e viveiro de formas jovens destas espécies de grande importância econômica para a região da Serra da Bodoquena (turismo) e sistema do Alto Rio Miranda e Pantanal (pesca esportiva e de subsistência).

A nascente da Baía Bonita também é palco de reprodução de peixes residentes. Destacam-se espécies do gênero Ancistrus e Crenicichla. O conhecimento da reprodução em Crenicichla lepidota é limitado principalmente a observações em aquário. Um estudo naturalístico conduzido na nascente da Baía Bonita relatou aspectos do comportamento reprodutivo e dos cuidados parentais deste ciclídeo (Sabino \& Andrade, 2003). A estratégia reprodutiva de Crenicichla lepidota, que envolve nidificação em micro-hábitats abrigados somados aos cuidados parentais, deve ampliar a chance de sobrevivência da prole em condições naturais. Entretanto, a passagem

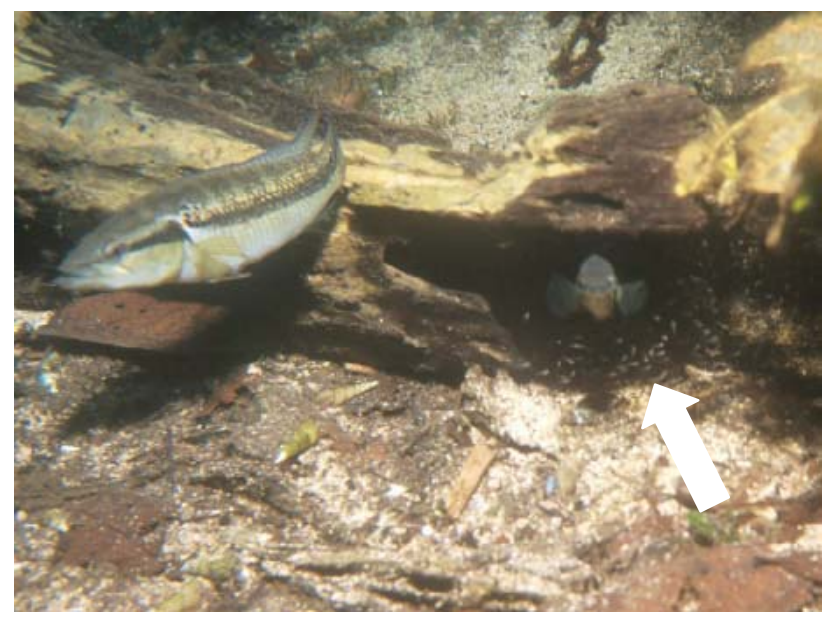

Figura 3. Casal de Crenicichla lepidota (macho à esquerda, fêmea à direita), protegendo prole em ninho de tronco submerso, após serem perturbados. Note os juvenis (seta), no entorno da fêmea, entocados sob perturbação (Foto: José Sabino, 14/01/2003). 
constante de visitantes perto dos ninhos, especialmente na área da nascente, e durante a alta temporada de janeiro (período que coincide com o pico de reprodução desta espécie), estressa estes peixes, que ficam a maior parte do tempo entocados e sem poder se alimentar (Figura 3).

Considerando a perturbação contínua da passagem dos visitantes, não é possível saber qual o sucesso reprodutivo de Crenicichla lepidota no local. Neste estudo, detectamos uma grande discrepância entre o número de ovócitos registrados nas fêmeas dissecadas e o número de larvas e juvenis registrados no campo (Sabino \& Andrade, 2003). É claro que deve haver uma perda das formas juvenis por predação ou morte natural, mas também é possível que parte da mortalidade seja conseqüência de pressões ambientais decorrentes do estresse causado pelo excesso de visitação.

Merece destaque o tratamento ambiental dado a situações similares em Fernando de Noronha: no período de desova e nidificação de aves marinhas, as trilhas de caminhamento próximas aos ninhos são interditadas para a visitação turística (Mitraud, 2001).

\section{Conservação da biota aquática}

Os estudos sobre monitoramento de impactos resultantes da visitação turística em ambientes de água doce Neotropicais são muito reduzidos, e praticamente inexistentes no Brasil (Sabino \& Andrade, 2002). A maioria das experiências brasileiras envolvendo análises sobre capacidade de carga, mitigação dos impactos decorrentes da visitação e monitoramento de áreas de visitação referese a ambientes terrestres (Takahashi, 1997) ou marinhos (Reuss-Strenzel et al., 1997).

Encontrar o equilíbrio entre o interesse econômico (privado) e a conservação ambiental (interesse público) não é tarefa fácil, principalmente porque o controle deste equilíbrio depende de critérios e fatores subjetivos e de políticas ambientais e turísticas adequadas. Um programa de monitoramento, cientificamente embasado, diminui esta subjetividade, pois inclui avaliação de componentes bióticos e abióticos quantificáveis (Sabino \& Andrade, 2002). Para as mitigar os impactos da visitação, por exemplo, há metodologias amplamente difundidas como a de "Capacidade de Carga" (Cifuentes, 1992), "Limite Aceitável de Câmbio" (Stankey, 1985; Takahashi, 1997) e "Visitor Impact Management" (Frêixedas-Vieira et al., 2000).

O monitoramento fornece a validação científica da operação de mínimo impacto, indicando sua sustentabilidade, ou não, em longo prazo. Desse modo, a informação ambiental tem papel estratégico na conservação e utilização sustentável da biodiversidade do ecossistema estudado. Estudos de monitoramento na região de Bonito deveriam ser reconhecidos pelos operadores locais como a forma mais segura de se buscar a sustentabilidade ambiental de longo prazo, e não como ameaça aos resultados financeiros imediatos. Monitorar as rupturas dos sistemas naturais e suas conseqüências deletérias constitui uma árdua tarefa científica, que necessita de estudos de ecologia de populações e comunidades em longo prazo (Goldsmith, 1994; Garay \& Dias, 2001). No caso da Baía Bonita, temos um conhecimento ainda muito precário dos organismos e suas complexas relações. Para evidenciar esta ignorância, há uma nova espécie de peixe sendo descrita da nascente do rio (Benine et al., no prelo), e, seguramente, há pelo menos quatro outras espécies que ocorrem na área e ainda não foram descritas pela Ciência.

\section{Valoração ambiental do ecoturismo na região de Bonito}

A valoração econômica da biodiversidade tem merecido esforço de estudo no Brasil e no mundo (e.g., Lindberg \& Huber-Jr, 1993; Araujo-Lima et al., 1998). Mas o que se perde com a alteração do mundo natural, de suas populações e ecossistemas? A depauperação da biodiversidade implica em perda de espécies, e perda de serviços prestados pelo funcionamento dos ecossistemas, como depuração do ar e da água, proteção do solo, regulação climática, além da perda da informação educacional e científica, e da inspiração cultural e estética (Wilson, 2002).

A título de exercício, qual seria a perda econômica de apenas um exemplar de piraputanga, Brycon hilarii, a principal espécie de interesse turístico na Baía Bonita? Para entendermos quanto vale apenas um indivíduo, temos as seguintes informações: a) a população desta espécie de peixe no Rio Baía Bonita é estimada em 500 indivíduos; b) se ao longo do ano passam, em média, cerca de 22 mil turistas pelo atrativo (fonte: COMTUR); c) estes visitantes pagam entre R \$ 55,00 (baixa temporada) e R \$ 90,00 (alta temporada) para visitar a Baía Bonita (Aquário Natural); d) considerando que a metade dos visitantes passa pelo atrativo na alta temporada e a outra metade na baixa, a empresa tem uma receita bruta aproximada de $\mathrm{R} \$ 1.595 .000,00$ ao ano. Desse modo, uma única piraputanga rende, ao ano, $\mathrm{R} \$ 3.190,00$ (1.595.000 dividido por 500). Considerando que cada piraputanga pode viver em condições naturais por volta de cinco anos, cada indivíduo da Baía Bonita tem potencial para gerar uma receita bruta média de $\mathrm{R} \$ 15.950,00$ em sua vida.

É evidente que esta equação trata-se de apenas um exercício, mas dá para se ter uma idéia da valoração da biodiversidade e, no caso específico, dos lucros advindos da administração de um empreendimento de turismo em Bonito, que explora as riquezas naturais. Entretanto, a conservação da natureza implica na colocação de valores éticos nestas equações, que transcendem o simples fluxo 
de caixa de uma empresa cuja fonte de renda é o mundo natural. A diversidade biológica é patrimônio da Humanidade e como tal deve ser tratada com absoluto respeito e ética. Em um plano mais prático e focado no exemplo da Baía Bonita, alterações da composição da flora aquática, com seu empobrecimento e/ou degradação, resultam invariavelmente em perdas da biota aquática, notadamente da ictiofauna, e fauna e flora ripárias com danos em suas complexas inter-relações.

\section{Conflito entre conservação e resultados financeiros imediatos}

No início de 2002 a empresa Baía Bonita Tours, que opera o passeio obteve da SEMA-MS a Licença de Operação (n⿳o 014/2002) com aumento da capacidade de carga de 100 turistas/dia para 200/dia (em grupos de 09 turistas mais 01 guia a cada meia hora, com 20 repetições diárias). Com o aumento de $100 \%$ do potencial de visitação, destacamos que os estudos de monitoramento deveriam ser mantidos para se obter avaliações contínuas das condições ambientais, visando a sustentabilidade ecológica do local. Vale ressaltar que a capacidade de carga total (200 pessoas/dia) é atingida principalmente durante a alta temporada de verão, período que coincide com o pico de reprodução das espécies residentes, como Crenicichla lepidota e Ancistrus spp., e migradoras, como Prochilodus lineatus e Brycon hilarii. Adicionalmente, a Baía Bonita é a única empresa da região que faz a operação turística dentro da área da nascente, diferentemente de outros passeios de flutuação que mantêm as áreas de nascentes intangíveis (Rio da Prata) ou apenas visitadas externamente (Rio Sucuri).

Considerando a unicidade, a delicadeza e a importância biológica dos ecossistemas existentes na Baía Bonita, notadamente a nascente do rio; considerando as pressões deletérias oriundas da visitação em 2002; e considerando as avaliações gerais que constatam a perda de parcela da biodiversidade, recomendamos fortemente, aos proprietários da empresa, à SEMA-MS e ao Ministério Público, a redução do número de visitantes de 180 para 120 ao dia.

Para que os peixes e o restante da biota possam interagir naturalmente, recomendamos também que o intervalo entre um grupo e outro de visitantes seja ampliado dos atuais 30 minutos para 45 minutos, contados a partir da saída da piscina de treinamento. Recomendamos, ainda, que cada grupo permaneça no máximo 10 minutos na nascente, de modo que mesmo nos períodos de pico de visitação a nascente e o próprio rio tenham pelo menos 30 minutos de intervalo entre a passagem de cada grupo de visitantes.

Infelizmente, as recomendações para redução dos impactos da visitação não foram acatadas pela Baía Bonita Tours, responsável pela operação turística do local. Ao contrário, a empresa contratou um biólogo que, após dois dias de visitas ao campo, teceu críticas ao estudo de três anos e rechaçou as orientações do monitoramento. Como qualquer produto científico, o Programa de Monitoramento do Rio Baía Bonita não é intocável, pois se trata de ferramenta nova e em contínuo aperfeiçoamento. Contudo, apesar de suas eventuais limitações, o Protocolo de Monitoramento e seus resultados atuais são o mais poderoso instrumento de que dispomos para avaliar as condições ambientais e a operação turística do Rio Baía Bonita. Consideramos que a execução das medidas mitigadoras sugeridas no monitoramento seja fundamental para que os objetivos de uso sustentável em longo prazo sejam alcançados.

Mesmo com a redução do número de visitantes, o empreendimento ainda é economicamente sustentável. Em nossa avaliação, o funcionamento com a capacidade atual de 200 pessoas/dia, resultará na "morte dos peixinhos dos ovos de ouro". A redução da visitação para 120 visitantes/ dia permitiria a operação do passeio por um tempo maior, além da manutenção da biodiversidade em longo prazo.

Para justificar a redução do número de visitantes, além dos quesitos científicos listados, atraímos a atenção do Poder Público para o "Princípio da Precaução", indicado na Convenção sobre Diversidade Biológica (CDB). Em seu preâmbulo, a Convenção declara: “observando também que quando exista ameaça de redução ou perda de diversidade biológica, a falta de plena certeza científica não deve ser usada como razão para postergar medidas para evitar ou minimizar essa ameaça". Desse modo, para a CDB, basta haver ameaça de redução ou risco de perda de diversidade biológica para que o "Princípio da Precaução" seja requerido.

O uso e a conservação da natureza não é uma atividade amadora e, como tudo no mundo moderno, envolve a ação de especialistas. Há todo um conjunto de referenciais teóricos e práticos embasados na Ciência da Ecologia e na Biologia da Conservação (e.g., Terborgh et al., 2002). Embora a preocupação e o desejo de conservar a Natureza sejam ideais amplamente difundidos na sociedade, a conservação efetiva se dá por meio de quesitos técnicos e hoje há um conjunto de teorias e métodos aplicáveis que permitem a gestão ambiental com mínimo impacto à Natureza (Wilson, 1988; 2002 Terborgh et al., 2002).

Empresários que usam a biodiversidade como fonte de recursos precisam reconhecer, não apenas no discurso, suas responsabilidades fundamentais sobre a conservação da biota e dos bens naturais existentes em áreas sob seu domínio. Uma empresa que vive da exploração dos recursos naturais não pode ter apenas o fluxo de caixa positivo como meta. Não é possível manter uma visão simplista e reducionista da atividade de exploração dos recursos naturais. O lucro puro e simples (direito privado) nunca pode suplantar os limites da Natureza e os princípios e a ética conservacionista (direito público). 
Ao nosso ver, a Licença de Operação não basta para proteger os ambientes. Existe forte pressão do capital sobre os ecossistemas da região de Bonito. Com a construção do aeroporto regional e a inauguração de novos hotéis, que em conjunto facilitarão o acesso à região, haverá maior pressão sobre os ecossistemas locais. Acreditamos que a sustentabilidade de ambientes frágeis como as nascentes e rios de Bonito somente será mantida se programas similares de monitoramento e proteção forem adotados nestes ecossistemas e, obviamente, respeitados pelos donos da terra e pelo Poder Público.

Seguramente, um programa de monitoramento continuado e cientificamente embasado, ao detectar alterações ambientais representa a melhor ferramenta para conciliar a exploração turística com a conservação dos ambientes em longo prazo. As informações ambientais apresentam-se hoje como fator estratégico para subsidiar o planejamento ambiental e o uso sustentável de recursos naturais (Garay \& Dias, 2001).

Acreditamos que há muito que fazer para proteger a região. Sob os aspectos de estudos biológicos, ainda estamos na fase de catalogação da fauna e flora da Bodoquena. A ciência da Ecologia pode e deve contribuir para elaboração de estudos focados na sustentabilidade do turismo local (e.g, Banducci \& Moretti, 2001; Cole \& Landers, 1996; Faria \& Carneiro, 2001; Sabino \& Andrade, 2002). Respeito e ética nas relações trabalhistas e técnicas também são requisitos fundamentais para a realização de estudos ecológicos de longo prazo. Esperamos que o maior conhecimento dos ecossistemas permita uma melhor gestão e que os interesses ecológicos fiquem sempre acima do interesse privado e comercial. Gostaríamos que estudos de monitoramento, como o implantado no Rio Baía Bonita, fossem aceitos como resultado de interações maduras entre a ciência e o empresariado, tendência em franca expansão no mundo moderno. Sabemos, contudo, que a aceitação destes produtos da ciência passa por um longo caminho de educação e de mudança de percepção de mundo sobretudo de empresários com visão retrógrada e obscura.

O modelo abjeto de concentração de renda, no qual cerca de $65 \%$ do valor bruto arrecadado ficam nas mãos do empreendedor, na forma de lucro, é outro ponto que merece repúdio de quem vê na natureza não apenas uma fonte de lucro fácil. Com este percentual de lucro, como justificar as perdas de parcela da biodiversidade ou a não repartição justa dos benefícios do uso da diversidade biológica, garantida por princípio na CDB? Sabemos que o lucro é a essência da sociedade capitalista, mas acreditamos que não se pode obtê-lo sem responsabilidade social e ambiental.

\section{Peixes são animais silvestres e Bonito mostra isso à sociedade}

O Brasil tem a maior riqueza de peixes de água doce do mundo, com estimativas que variam entre 4000 e 5000 espécies (Sabino \& Prado, no prelo). Grande parte destes peixes vive em ambientes de águas escuras ou barrentas. As nascentes e rios da região da Bodoquena formam cenários ideais para contato com parte deste imenso patrimônio natural. A região é uma excelente janela para observação de ambientes de água doce e seus organismos. Suas águas dão um verdadeiro banho de sensibilização ambiental.

Vertebrados constituem as criaturas mais importantes e evidentes para os seres humanos, e muitas delas são usadas como espécies-símbolo em programas de conservação (e.g., mico-leão-dourado, muriqui, arara-azul, tamanduá-bandeira, tartaruga-marinha) e ecoturismo (e.g., Walpole \& Leader-Willliams, 2002). Mittermeier (1988) destaca a empatia do público para o que chama de megavertebrados carismáticos, considerados o melhor veículo para divulgação e popularização da questão conservacionista. Ao contrário de mamíferos e aves, os peixes não atraem tanto a opinião pública para aspectos de

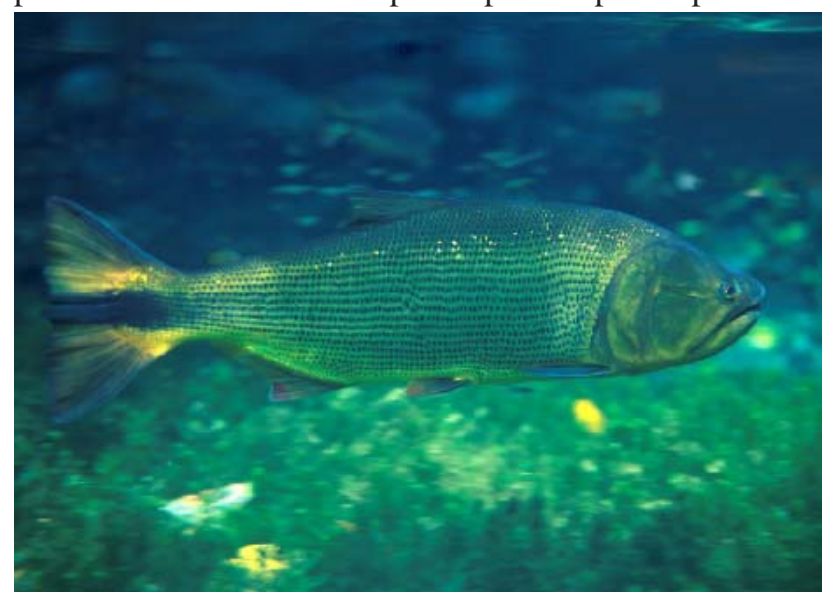

Figura 4. O monitoramento rio Baía Bonita está focado principalmente nas observações subaquáticas de espécies que ocupam posição de topo na cadeia alimentar, como o dourado, Salminus maxillosus (Foto: José Sabino, 21/03/2002).

conservação. De modo geral, predomina o pensamento de que rios e mares são fontes inesgotáveis de recursos e que são estes ambientes pouco afetados pelas interferências humanas (Greenwood, 1992). Na região do Planalto da Bodoquena, peixes deixam de ser "recursos pesqueiros" ou apenas "animais fedidos" e viram objetos de admiração.

A conservação de ambientes frágeis, como nascentes, rios e matas ripárias da Bodoquena, somente será possível se houver pesquisas ecológicas e um amplo planejamento do turismo. Mais que isso, implantar técnicas de uso racional e sustentável nestes ambientes mostra que o ecoturismo pode ser uma importante ferramenta na conservação da biodiversidade. $\mathrm{E}$ isso poderia ser um bom exemplo para o Brasil e para o mundo. 
Finalmente, reafirmamos nossa absoluta admiração pelo mundo natural. Temos a convicção que a Natureza pode ser usada de modo respeitoso e ao mesmo tempo preservada em sua plenitude, proporcionando uma vida harmoniosa a todos os seres.

\section{Agradecimentos}

Somos gratos à Fundação Manoel de Barros e à Fundação de Apoio ao Desenvolvimento do Ensino, Ciência e Tecnologia do Estado do Mato Grosso do Sul -Fundect/ CNPq pelo apoio financeiro (Processo no 21/030027/02). Eleonora Trajano, Jansen Zuanon e Ricardo Macedo Corrêa e Castro deram importantes sugestões ao estudo de caracterização da ictiofauna e monitoramento do rio Baía Bonita. Finalmente, agradecemos ao Reitor da UNIDERP, Professor Pedro Chaves dos Santos Filho, que nos apoiou em todos os momentos deste confronto entre o Brasil velho e o Brasil novo, entre a visão obscura, hostil e retrógrada dos proprietários e gerente da Baía Bonita Tours e as evidências e a clareza do método científico. Este confronto ainda não acabou, mas temos certeza que o Brasil novo vencerá, tal e qual antevê Cláudio de Moura e Castro em sua coluna da revista Veja, "O mato não é treva" (edição 1810).

\section{Referências Bibliográficas}

Araújo-Lima, C.A.R.M., M. Goulding, B. Forsberg, R. Victoria \& L. Martinelli, 1998. The economic value of the Amazonian flooded forest from a fisheries perspective. Verh. Internat. Verein. Limnol., 26: 2177-2179.

Banducci-Jr., A. \& E.C. Moretti (orgs.), 2001. Qual Paraíso? Turismo e Ambiente em Bonito e no Pantanal. Edições Chronos e Editora da UFMS. 205p.

Benine, R.C.; R.M.C. Castro \& J. Sabino, no prelo. Moenkhausia sp.n., a new species from Pantanal, Rio Paraguai Basin, MS, Brazil (Characiformes: Characidae). Copeia.

Boggiani, P.C., 1999. Geologia da Bodoquena. Pp.10-23. In: Nos jardins submersos da Bodoquena: guia para identificação de plantas aquáticas de Bonito e região. Scremin-Dias, E.; Pott, V.J.; Hora, R.C. \& Souza, P.R. (eds.). Editora da Universidade Federal de Mato Grosso do Sul. 160p.

Bratton, S.P., 1985. Effects of disturbance by visitors on two woodland orchid species in Grea Smoky Mountains National Park, USA. Biological Conservation, 31: 211227.
Cifuentes, M., 1992. Determinación de capacidad de carga turística en áreas protegidas. Turrialba: Centro Agronómico Tropical de Investigación y Enseñanza CATIE.

Cole, D.N.,1993. Minimizing conflict between recreation and nature conservation. Pp. 105-122. In: Ecology of greenways: Design and function of linear conservation areas. D.S.Smith \& P.C. Hellmund (eds.). University of Minnesota Press, Minneapolis.

Cole, D.N., 2000. Biophysical impacts of wildland recreation use. Pp. 257-264. In: Trends in outdoor recreation, leisure and tourism. W.C. Gartner \& D.W. Lime (eds.). CAB International.

Cole, D.N. \& P.B. Landres, 1996. Threats to wilderness ecosystems: impacts and research needs. Ecological Applications, 6(1): 168-184.

Faria, D.S. \& K.S.Carneiro, 2001. Sustentabilidade ecológica no turismo. Editora da UnB. $96 \mathrm{p}$.

Frêixedas-Vieira, V.M.; A.J. Passold,; T.C. Magro, 2000. Impactos do Uso Público: um guia de campo para utilização do método VIM. Pp. 296-305. In: Congresso de Unidades de Conservação, 2, Campo Grande, MS. Anais, vol II. Campo Grande: Rede Pró-Unidades de Conservação, Governo de Mato Grosso do Sul, Fundação O Boticário de Proteção à Natureza.

Garay, I. \& B.F.S. Dias, 2001. Conservação da Biodiversidade em Ecossistemas Tropicais: avanços conceituais e revisão de novas metodologias de avaliação $e$ monitoramento. Editora Vozes. Petrópolis. 430p.

Garber, S.D. \& J. Burger, 1995. A 20-YR study documenting the relationship between turtle decline and human recreation. Ecological Applications, 5(4): 1151-1162.

Goldsmith, F.B., 1994. Monitoring for Conservation and Ecology. Chapman \& Hall. London, UK.

Greenwood, P.H., 1992. Are the major fish faunas wellknown? Journal of Zoology, 42: 131-138.

Lindberg, K. \& D.E. Hawkins (eds.), 1993. Ecotourism: a guide for planners \& managers. The Ecotourism Society. North Bennington, Vermont, $175 \mathrm{p}$.

Mittermeier, R.A., 1988. Primate diversity and the tropical forest. Pp.145-154. In: Wilson, E.O. (ed.). Biodiversity. Washington DC, National Academy Press. 521p.

Mitraud, S.F. (coord.), 2001.Uso Recreativo do Parque Nacional Marinho de Fernando de Noronha: um exemplo de planejamento e implementação. WWF Brasil, Brasília. 100p.

Niefer, I. \& J.C.L.G.Silva, 1999. Critérios para um ecoturismo ambientalmente saudável. Cadernos da Biodiversidade, 2(1): 53-61.

Pott, V.J. \& A. Pott, 2000. Plantas Aquáticas do Pantanal. Embrapa, Brasília. 404p. 
Reuss-Strenzel, G.M.; M.L. Asmus; A.P. Chludinski, 1997. Avaliação inicial do impacto causado pelo turismo submarino na Reserva Biológica do Arvoredo - Santa Catarina, Brasil utilizando um modelo ecológico de simulação. pp. 528-541. In: Anais do I Congresso Brasileiro de Unidades de Conservação, vol. II. IAP/ UNILIVRE, Curitiba, Brasil.

Reys. P.; J. Sabino, \& M. Galetti, 2000. Frugivory and seed dispersal by the fish Brycon microlepis (Characidae) and other frugivores in a riverine forest in Bonito, Western Brazil. Pp. 247. 3rd International Symposium - Workshop on Frugivores and Seed Dispersal. São Pedro, Brazil.

Rizzo, H.G., 2001. Programa nacional de monitoramento ambiental integrado - Monitore. Conservação da Biodiversidade em Ecossistemas Tropicais: avanços conceituais e revisão de novas metodologias de avaliação e monitoramento. Pp. 59-67. In: Garay, I. \& B.F.S. Dias (eds.). Editora Vozes. Petrópolis. 430p.

Roggenbuck, J.W. \& R.C. Lucas, 1987. Wilderness use and user characteristics: a state of knowledge review. General Technical Report. USDA Forest Service, Fort Collins, USA.

Sabino, J., 1999. Comportamento de peixes em riachos: métodos de estudo para uma abordagem naturalística. pp. 183-208. In: Ecologia de Peixes de Riachos. Caramaschi, E.P.; R. Mazzoni, \& P.R. Peres-Neto (eds.). Série Oecologia Brasiliensis, vol. VI. PPGE-UFRJ, Rio de Janeiro, Brasil.

Sabino, J., 2002. Planalto da Bodoquena: Natureza em estado de graça. Revista Os Caminhos da Terra, 125: 58-65.

Sabino, J. \& L.P.Andrade, 2002. Monitoramento e conservação no rio Baía Bonita, região de Bonito, Mato Grosso do Sul, Brasil. Pp. 397-404. In: Anais do III Congresso Brasileiro de Unidades de Conservação. Rede Pró-Unidades de Conservação, Fundação Boticário de Proteção à Natureza e Associação Caatinga. Fortaleza, Ceará. 876p.

Sabino, J. \& L.P. Andrade, 2003. Comportamento reprodutivo e cuidados parentais da joaninha Crenicichla lepidota (Cichlidae) no sistema do Rio Formoso, Bonito, Mato Grosso do Sul. CD-Rom. XV Encontro Brasileiro de Ictiologia. Universidade Metodista Mackenzie, São Paulo.

Sabino, J. \& I. Sazima, 1997. A comunidade de peixes da nascente da Baía Bonita, em Bonito, Mato Grosso do Sul. XII Encontro Brasileiro de Ictiologia, IOUSP, São Paulo.

Sabino, J. \& I. Sazima, 1999. Association between fruiteating fish and foraging monkeys in western Brazil. Ichthyological Explorations of Freshwaters, 10 (4): 309312.
Sabino, J. \& P.I. Prado, no prelo. Síntese do Conhecimento da Diversidade de Vertebrados do Brasil. Série Biodiversidade. Ministério do Meio Ambiente e Programa das Nações Unidas para o Desenvolvimento (PNUD - ONU).

Sánchez-Botero, J.I. \& C.A.R.M. Araújo-Lima, 2001. As macrófitas aquáticas como berçário para ictiofauna da várzea do Rio Amazonas. Acta Amazônica, 31 (3): 437447.

Stankey, G.; D. Cole; R. Lucas; M. Petersen; S. Frissell, 1985. The limits of acceptable change (LAC) system for wilderness planning. General Technical Report INT-176. Ogden, UT: U.S. Department of Agriculture, Forest Service, Intermountain Research Station.

Takahashi, L.Y., 1997. Limite aceitável de câmbio (LAC): Manejando e monitorando visitantes. Pp. 445-464. In: Anais do I Congresso Brasileiro de Unidades de Conservação, vol. I. IAP/UNILIVRE, Curitiba.

Terborgh, J.; C. van Schaik; L. Davenport \& M. Rao, 2002. Tornando os parques eficientes: estratégias para conservação da natureza nos trópicos. Curitiba. Editora da UFPR. Fundação O Boticário de Proteção à Natureza.

Tolmasquim, M.T., 2001. Estrutura conceitual para a elaboração de indicadores de sustentabilidade para o Brasil. Pp. 68-75. In: Conservação da Biodiversidade em Ecossistemas Tropicais: avanços conceituais $e$ revisão de novas metodologias de avaliação $e$ monitoramento. Garay, I. \& B.F.S. Dias (eds.). Editora Vozes. Petrópolis. 430p.

Walpole, M.J. \& N. Leader-Williams, 2002. Tourism and flagship species in conservation. Biodiversity and Conservation, 11: 543-547.

Wilson, E.O., 1988. Biodiversity. Washington DC, National Academy Press. 521p.

Wilson, E.O., 2002. O Futuro da Vida. Rio de Janeiro, Editora Campus. 242p.

Título: Uso e conservação da ictiofauna no ecoturismo da região de Bonito, Mato Grosso do Sul: o mito da sustentabilidade ecológica no Rio Baía Bonita (Aquário Natural de Bonito)

Autores: José Sabino \& Luciana Paes de Andrade

Biota Neotropica, Vol. 3 ( number 2): 2003

http://www.biotaneotropica.org.br/v3n2/pt/ abstract?point-of-view+BN00403022003

Recebido em 18/06/2003

Publicado em 01/07/2003

ISSN 1676-0603 